\title{
Emission of particulate matter during aircraft landing operation
}

\author{
Remigiusz Jasiński1,a, Jacek Pielecha ${ }^{1}$ and Jarosław Markowski ${ }^{1}$ \\ ${ }^{1}$ Poznan University of Technology, Institute of Combustion Engines and Transport, 60-965, Poznan, Poland
}

\begin{abstract}
The article presents the results of studies conducted in the area adjacent to the airport located in Poznan, to determine the impact of aircraft landing operation on the concentration of particulate matter. Measurements were carried out using Engine Exhaust Particle Sizer Spectrometer 3090, enabling the measurement of the particle size distribution. The research allowed to determine the nature of the emitted particles and adds to the evaluation of impact on air quality. The tests were carried out during four aircraft landing operations. In each of the four cases total concentration of particulates number before landing (reference level) and during the landing of the aircraft was measured. In addition, the size distribution of reference level particles and its change after the landing operation was measured. Based on the conducted research, it was found that landing aircrafts have a significant impact on the concentration of particulate matter in the area adjacent to the airport. A single landing operation causes an substantially increase of the value of particle number concentration.
\end{abstract}

\section{Introduction}

Deterioration of atmospheric air quality in particular in urban areas results in various types of efforts to reduce toxic emissions. Currently one of the biggest problems concerning the air in urban areas is the increased concentration of particulate matter [1], resulting in a reduction of visibility in the form of smog and negative effects on human health appearing as diseases of the heart and lungs [2, 3]. Legislative measures taken by the authorities of the European Union are focused on reducing emissions of harmful compounds from automotive vehicles, however, more and more attention in particular scientific community attracts exhaust emissions from aircraft engines.

One of the fundamental issues in the assessment of air quality is the concentration of particulate matter. Particulate matter is a term generally used to describe a type of air pollutant, consisting of different particles mixtures, which differ in size, composition and spot of formation. The main sources of creating this type of pollution are: factories, power plants, incinerators, motor vehicles and many others. The basic division of solid particles due to their aerodynamic diameter, allowed for the determination of two main groups: PM2.5 and PM10 (Particulate Matter) diameter respectively of less than $2.5 \mu \mathrm{m}$ and $10 \mu \mathrm{m}$ [4]. The dynamic development of research topics related to particulate matter properties change depending on their size forced an introduction of a more detailed division [5]. It was assumed that the smallest particles (ultrafine particles) have a diameter of less than $0.1 \mu \mathrm{m}$ and fine particles (nanoparticles) less than $1 \mu \mathrm{m}$.
In recent years, more and more attention is paid to the emissions in areas of airports, due to the rapid increase of the air traffic volume and the outlook of further development in order to meet the transport needs for the subsequent years. Most of the research and publications indicate inadequate explanation of the phenomena which are the subject of intensive research because as the literature shows air transport emissions can significantly affect the quality of the air in the vicinity of airports and their surroundings [6].

Aircraft engines is just one of the many sources of pollution in the area of airports. It is widely recognized that aircraft emissions is responsible for most of the pollution in areas of airports, but it is necessary to be aware of other sources particularly dangerous at local scale. Among them we can point the products of wear of tires, brakes and runways. In addition the strong air turbulence generated by aircraft leads to resuspend these pollutants in the air. Physical and chemical characteristics of particulate matter generated in the tribological process were based only on a few publications [7], which indicates a strong need to develop this issue $[8,9]$.

Increasing knowledge of the processes in the aircraft engines and the dynamic development of the measuring devices necessitate the creation of new standards and rules for aircraft engines certification. The first emission standards for aircraft engines were introduced in the late 70s of XX century by the International Civil Aviation Organisation (ICAO). The key rules related to reduce the emission of harmful compounds from the aircraft were introduced by ICAO in Volume II of Annex 16 to the Convention on International Civil

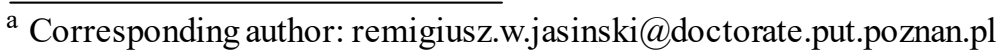


Aviation [10]. In this document, the recommendations relating to the measurement of carbon monoxide, nitrogen oxides, hydrocarbons and smoke were introduced.

These actions led to a significant reduction in direct emissions of harmful compounds from aircraft in the past twenty years. However the benefit may be offset by the increasing air traffic, due to the dynamic growth of air transport. In addition, the regulation introduced by ICAO applies only to the four main pollutants. In order to proper assess of the exhaust emissions more thorough analysis is required, including the analysis of chemical, physical and numerical characteristic of particle matters emitted by aircraft engines. The literature leaves a lot of questions in terms of emission of harmful compounds from aircraft in real traffic conditions, and it results in particular from the use of different methods of measurement, different way of presenting the results and the method of analysis of the research results $[11,12]$.

\section{Methodology}

\subsection{Purpose of the research}

The study was conducted in the vicinity of Poznan airport in western Poland. Location of the airport enforces frequent flights over the city center. Low altitude does not allow dilution of harmful compounds, as it is in the case of upper atmosphere level on a standard cruising altitude. It can be assumed that air transport has a negative impact on air quality over the area of airport (especially in the Poznan agglomeration). Large values of pollutants concentration in the Poznan air confirm reports of institutions established for air quality control. In 2014, it was found more than twice the permissible number of days with exceeded the norm PM10. The bad condition of the air is caused by all kinds of pollution sources, among other aircraft. The aim of the study was to evaluate the impact of landing aircraft on the numerical concentration of particulate matter in the area of Poznan airport.

\subsection{Test objects}

The objects of the research were cruise passenger aircraft, Boeing 737-500 (Fig. 1) and Boeing 737-800 (Fig. 2) landing at the Poznan-Lawica airport. These aircraft were selected because of their high frequency of landings in Poznan, which allowed for an increase in measurement attempts.

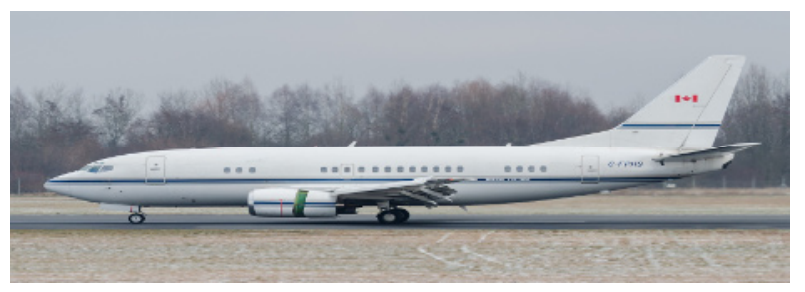

Figure 1. View of passenger plane Boeing 737-500.

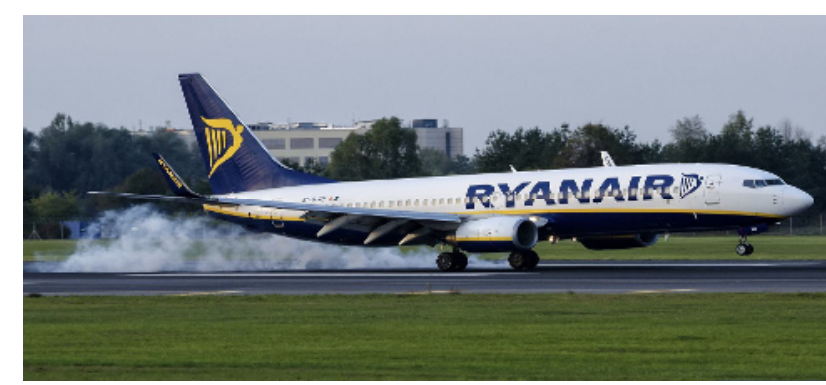

Figure 2. View of passenger plane Boeing 737-800.

Selected versions of the Boeing 737 in addition to the differences in the construction of the airframe, differed in applied jet engines. In the case of the Boeing 737-500 was CFM56-3 engine, while the Boeing 737-800 was equipped with CFM56-7B engines. Basic technical parameters of these engines were included in Table 1 .

Table 1. Technical parameters of aircraft.

\begin{tabular}{|l|c|c|}
\hline Parameter & $\begin{array}{c}\text { CFM56-3 } \\
\text { (Boeing 737-500) }\end{array}$ & $\begin{array}{c}\text { CFM56-7B } \\
\text { (Boeing 737-800) }\end{array}$ \\
\hline Maximum thrust $[\mathrm{kN}]$ & 89 & 95 \\
\hline Bypass ratio & 6.0 & 5.3 \\
\hline $\begin{array}{l}\text { Airflow (takeoff } \\
\text { conditions) }[\mathrm{kg} / \mathrm{s}]\end{array}$ & 300 & 320 \\
\hline
\end{tabular}

\subsection{Research method}

The measurements were carried out near the airport Poznan-Lawica, approximately $2 \mathrm{~km}$ from the aircraft touchdown point. In the day of the measurements there was no rain, and the wind speed did not exceed $12 \mathrm{~km} / \mathrm{h}$. Measuring device was set in the axis of approaches passenger aircraft. Measurement of particle number concentration was performed 4 times during the landing of each aircraft.

For measuring the size distribution of particle matters and their total concentration in the air a spectrometer TSI Incorporated - EEPS 3090 (Engine Exhaust Particle Sizer Spectrometer) was used (Fig. 3). It enabled the measurement of a discrete range of particle diameters (from $5.6 \mathrm{~nm}$ to $560 \mathrm{~nm}$ ) on the basis of their differing speeds. The degree of electric mobility of particulate matter is changed exponentially, and measurement of their size is carried out at a frequency of $10 \mathrm{~Hz}$. In order to reduce the impact of dust located at the ground, probe was placed on a stand with a height of $4 \mathrm{~m}$.

Tests were carried out on four aircraft in the order shown in Table 2. In each of the four cases total particle matter concentration before landing (reference test) and during the landing of the aircraft was measured. In addition, the size distribution of PN (particle number) before and after aircraft landing operation was measured. 


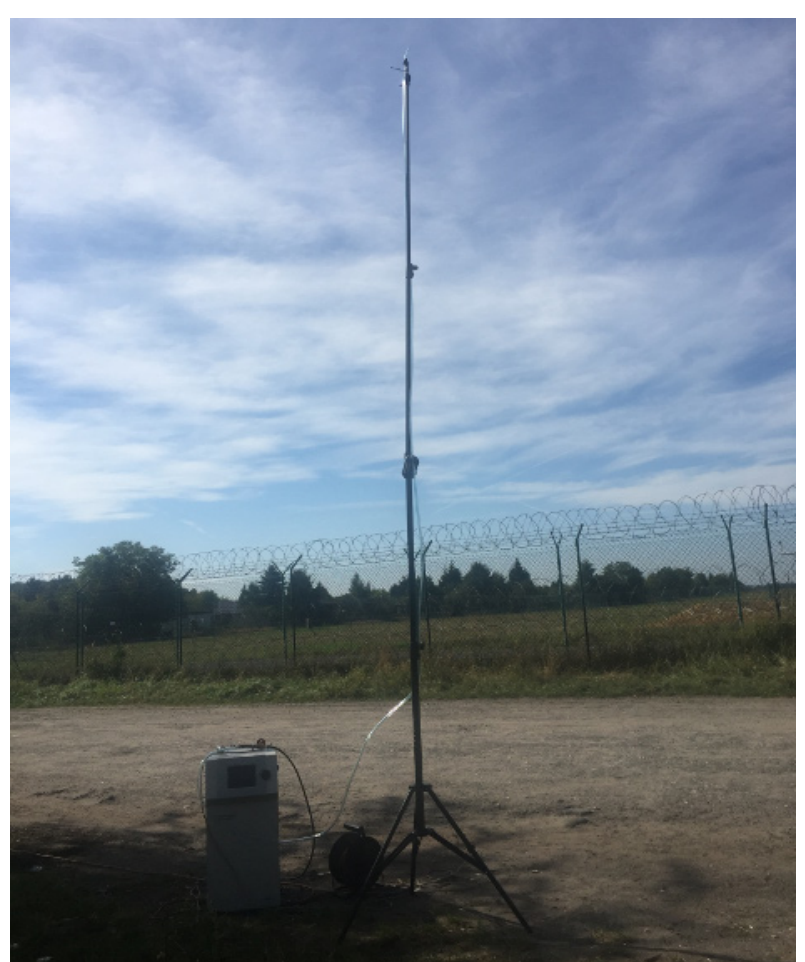

Figure 3. Mass spectrometer EEPS 3090.

Table 2. List of tested aircraft.

\begin{tabular}{|l|l|l|l|}
\hline & Date & Aircraft & Engine \\
\hline 1 & 17.09 .2015 & Boeing 737-800 & CFM56-7B \\
\hline 2 & 17.09 .2015 & Boeing 737-800 & CFM56-7B \\
\hline 3 & 17.09 .2015 & Boeing 737-800 & CFM56-7B \\
\hline 4 & 17.09 .2015 & Boeing 737-500 & CFM56-3 \\
\hline
\end{tabular}

\section{Measurement results and their analysis}

Parameterization of the emission limits from aviation engines shown in Annex 16 of the ICAO. Convention provides information on the exhaust smoke. In order to expand the information about the quality of exhaust gases from jet engines the studies of size distribution of particulate matters have been carried out. Using the measurement apparatus the diameter distributions of particles were determined.

The first aircraft was Boeing 737-800 equipped with CFM56-7B engine. The total average concentration of particles in the air immediately before the first aircraft landing was $3,2 \cdot 10^{3} \mathrm{~cm}^{-3}$. During the landing operation the concentration of PN increased 47-fold to $1,5 \cdot 10^{5} \mathrm{~cm}^{-3}$ (Fig. 4). The increased particulate concentration was maintained for about 60 seconds.

In the case of the PN size distribution of the first aircraft particles with diameters of 5-15 nm were dominated (Fig. 5). The characteristic value of the diameter of the particles (the most common) obtained distribution was $9 \mathrm{~nm}$. Particles with diameters greater than $20 \mathrm{~nm}$ were negligible part of the total concentration of $\mathrm{PN}$.
The average concentration of $\mathrm{PN}$ in the air before landing the second plane was slightly different compared to the level before landing the first plane and amounted to $2.8 \cdot 10^{3} \mathrm{~cm}^{-3}$ (Fig. 6). The average concentration of particulates during landing operation of the second airplane reached $2.7 \cdot 10^{5} \mathrm{~cm}^{-3}$. A 96-fold increase in the number concentration of particulate matter was found. The Increased concentration was maintained for about 110 seconds.

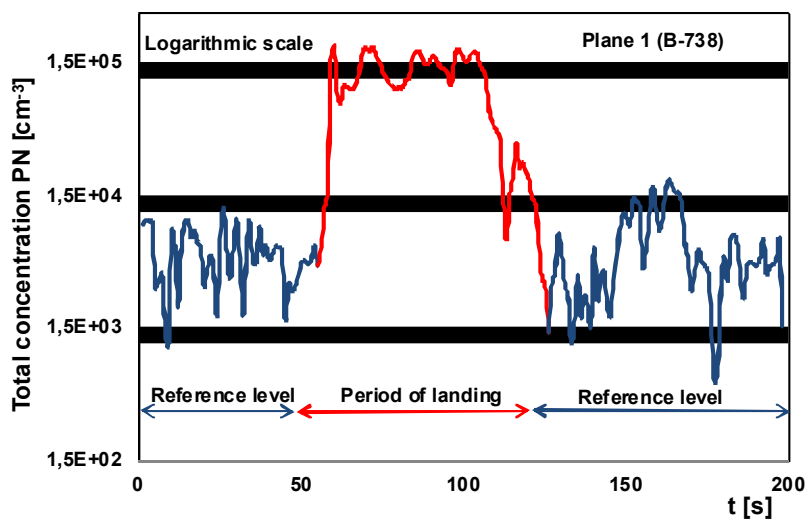

Figure 4. Total concentration of $\mathrm{PN}$ obtained for first aircraft.

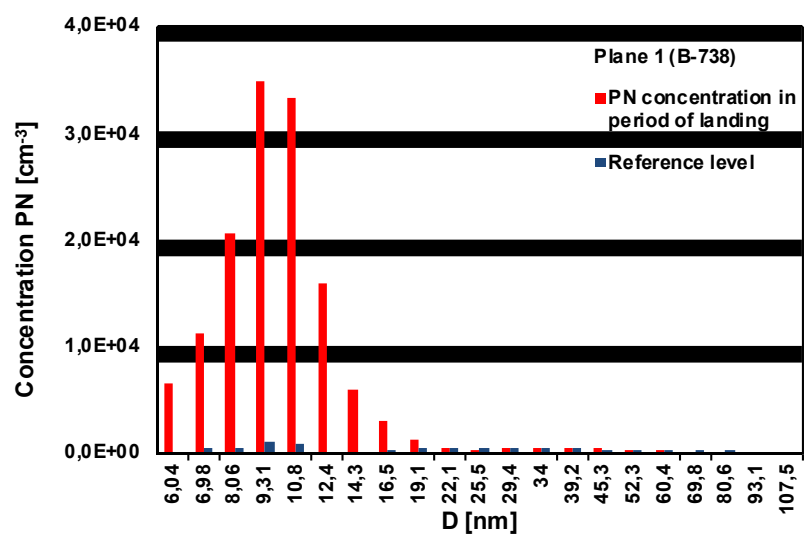

Figure 5. Size distribution of $\mathrm{PN}$ obtained for first aircraft.

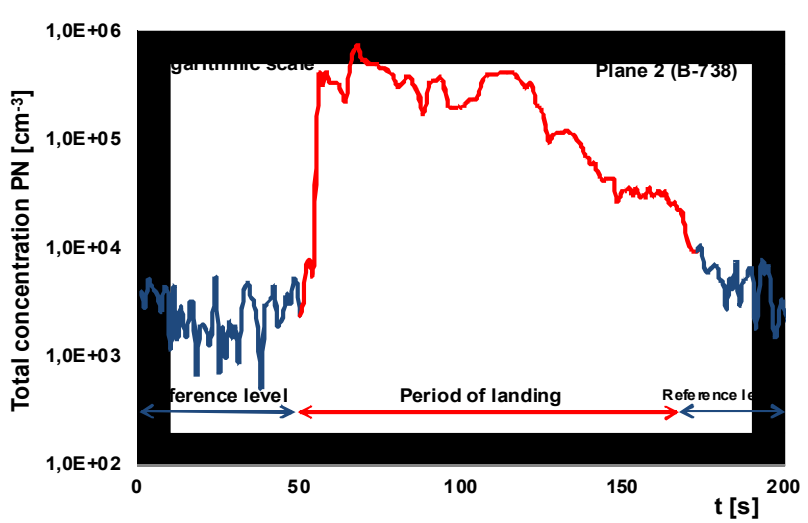

Figure 6. Total concentration of $\mathrm{PN}$ obtained for first aircraft.

Size distribution of $\mathrm{PN}$ during the second landing was not significantly different from the distribution obtained for the first plane (Fig. 7). Similarly, particles with the smallest diameters $(5-20 \mathrm{~nm})$ were dominant. The characteristic diameter value of obtained size distribution was $10 \mathrm{~nm}$. No increase in the concentration of PN with diameters greater than $40 \mathrm{~nm}$ was found. 
The effect of the third airplane landing was a 20 -fold increase in particulate concentration of $3,8 \cdot 10^{3} \mathrm{~cm}^{-3}$ to $7.9 \cdot 10^{4} \mathrm{~cm}^{-3}$ (Fig. 8). The increased particulate concentration in the test area was maintained for about $100 \mathrm{~s}$.

Size distribution as for other aircraft equipped with an engine CFM56-7B was characterized by the presence of PN from the range 5-15 nm (Fig. 9). The values of concentration of particles with diameters greater than $20 \mathrm{~nm}$ was negligible.

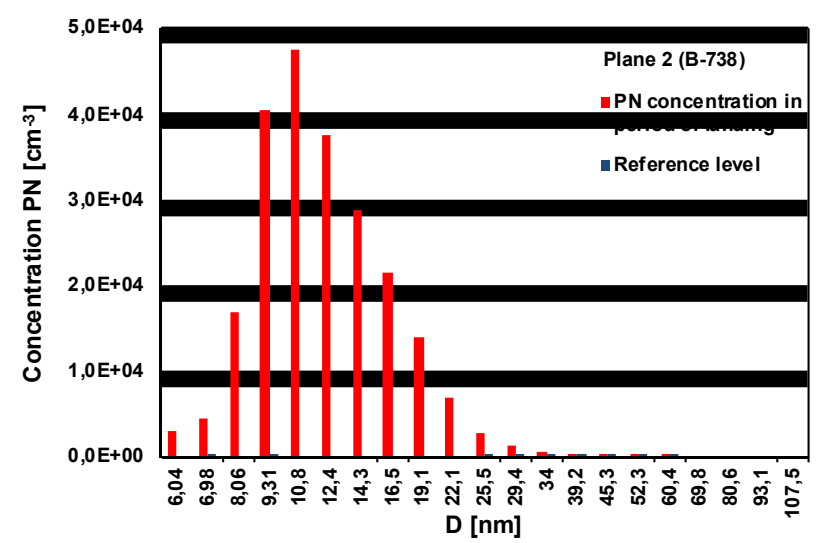

Figure 7. Size distribution of PN obtained for second aircraft.

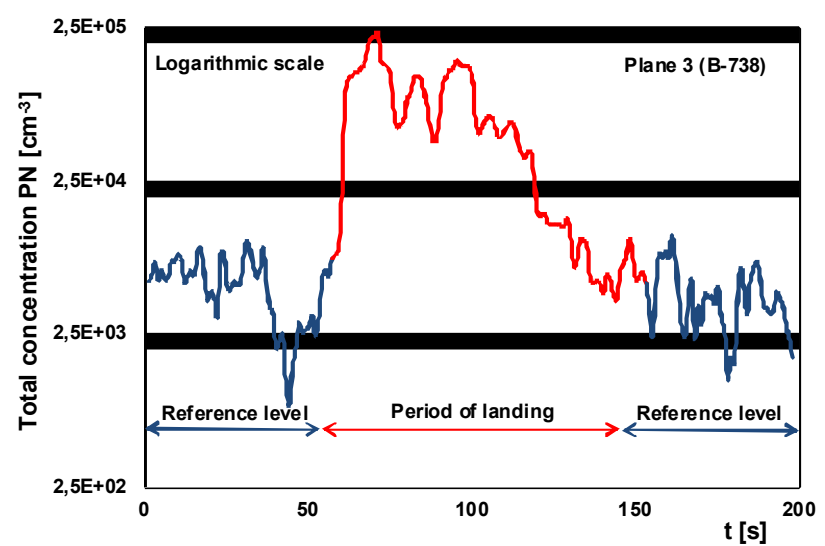

Figure 8. Total concentration of $\mathrm{PN}$ obtained for third aircraft.

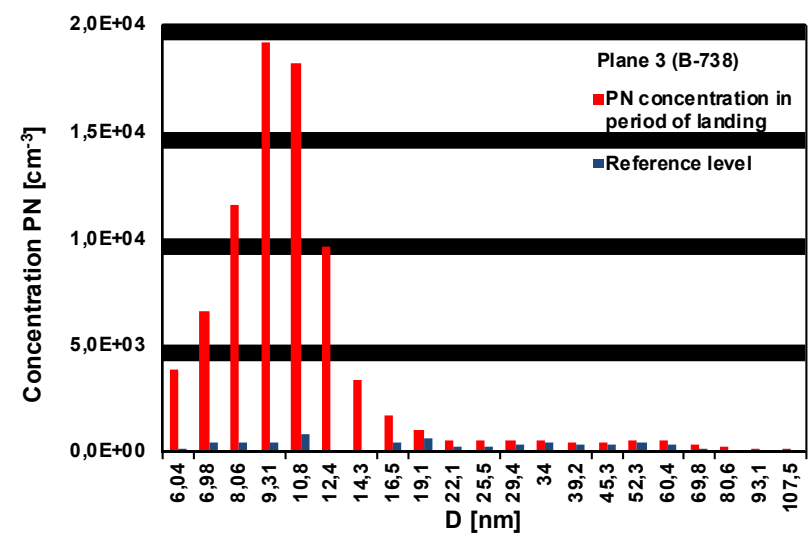

Figure 9. Size distribution of $\mathrm{PN}$ obtained for third aircraft.

The result of fourth passenger plane approach was a 18-fold increase in the average particle number concentration to of $6.9 \cdot 10^{4} \mathrm{~cm}^{-3}$ (Fig. 10). Increased concentration was maintained for a period of about 60 seconds.
Size distribution obtained in result of measurements during the fourth aircraft landing operation was significantly different from the distributions obtained for the other aircraft. In addition to the dominant particle number in the range of 6-10 $\mathrm{nm}$ increased concentrations of particulate characterized by diameters of $15-40 \mathrm{~nm}$ was observed (Fig. 11). On the basis of obtained size distribution two characteristic values of diameters (10 nm and $22 \mathrm{~nm}$ ) can be pointed. No significant increase in the concentration of particles of a size greater than 50 $\mathrm{nm}$ was found. The differences between the resulting size distribution obtained for the fourth airplane and distributions obtained for other test objects were caused by differences in the design of the fourth aircraft engine. Dimensional distribution of particulates obtained for aircraft equipped with the older model CFM56 engine (fourth object) shows similarity to the characteristic size distribution of particulates contained in the exhaust of motor vehicles.

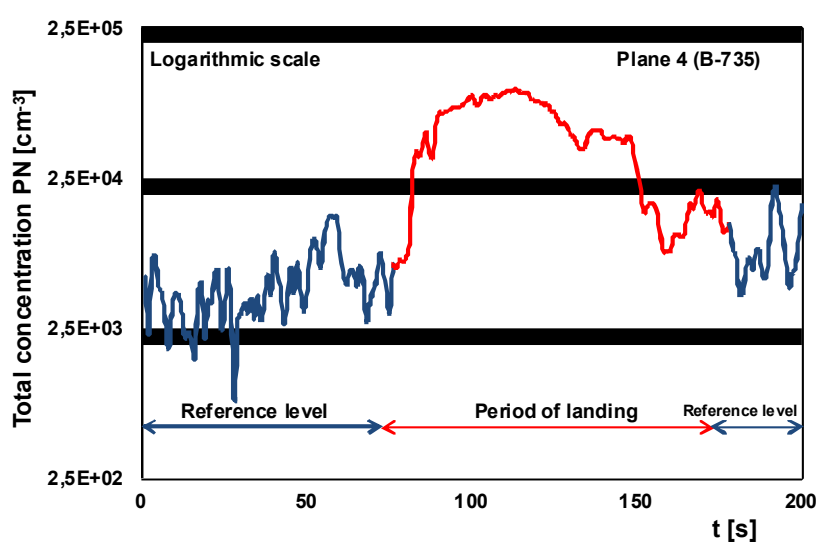

Figure 10. Total concentration of $\mathrm{PN}$ obtained for fourth aircraft.

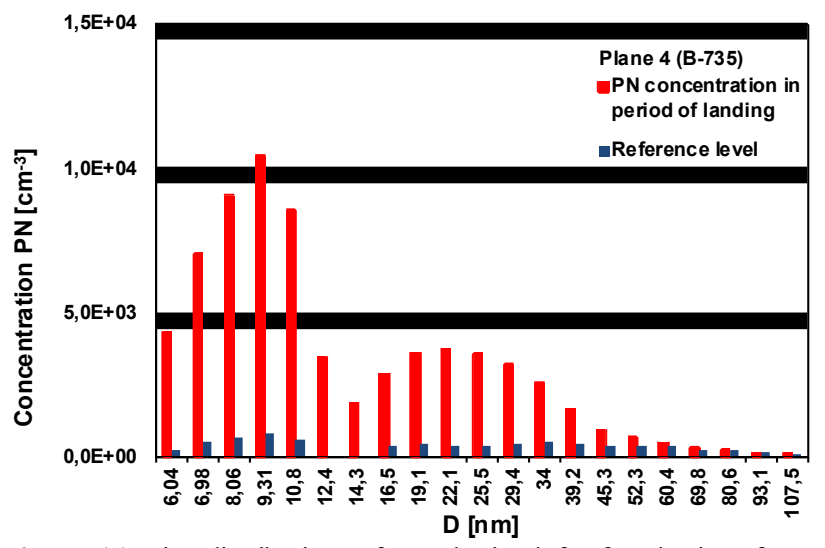

Figure 11. Size distribution of PN obtained for fourth aircraft.

\section{Summary}

On the basis of the measurements it was found that an aircraft approach causes significant effect on the quality of air in the area adjacent to the airport. The main symptom is a change in the concentration of particulate matter of diameter less than $100 \mathrm{~nm}$. A single landing operation causes an increase of the value of particle number concentration tens of times. The increased number of particulates in the air is 
maintained for a period of not less than 60 seconds. The resulting particle size distributions indicate that particulate matter emitted by the aircraft engine are characterized by a set of dimensions in the range of 5-40 $\mathrm{nm}$. This fact is significant that these particles are most harmful to human health.

There were significant changes in size distribution of PN depending on the jet engine. The older generation engines emit particles with a distribution similar to the distributions derived from motor vehicles. The fact that the measurements was performed at a distance of about $2 \mathrm{~km}$ from the aircraft touchdown point, suggests that areas of the runway, taxiways and aprons can be much more polluted than the area where the tests were carried out. This is particularly important in the context of workers of ground handling service.

\section{References}

1. V. Ramanathan, Y. Feng, Atmos. Environ. 43, 37-50 (2009)

2. M. Masiol, R.M. Harrison, Atmos. Environ. 95, 409455 (2014)

3. N.P. Hyslop, Atmos. Environ. 43, 182-195 (2009)

4. M. Kampa, E. Castanas, Environ. Pollut. 151, 362367 (2008)

5. F. Amato, T. Moreno, M. Pandolfi, X. Querol, A. Alastuey, A. Delgado, M. Pedrero, N. Cotsc, J. Environ. Monitor. 12, 854-862 (2010)

6. D.S. Lee, G. Pitari, V. Grewec, K. Gierens, J.E. Penner, A. Petzold, M.J. Prather, U. Schumann, A. Bais, T. Berntsen, D. Iachetti, L.L. Lim, R. Sausen, Atmos. Environ. 44, 4678-4734 (2010)

7. M. Bennett, S.M. Christie, A. Graham, B.S. Thomas, V. Vishnyakov, Environ. Sci. Tech. 45, 3533-3538 (2011)

8. A. Unal, Y. Hu, M.E. Chang, M.T. Odman, A.G. Russel, Atmos. Environ. 39, 5787-5798 (2005)

9. H. Peace, J. Maughan, B. Owen, D. Raper, Environ. Modell. Softw. 21, 532-538 (2006)

10. ICAO, Environmental Protection (Annex 16) Aircraft Engine Emission, International Standards and Recommended Practices 2 (2008)

11. M. Mazaheri, G.R. Johnson, L. Morawska, Atmos. Environ. 45, 3500-3507 (2011)

12. H. Agrawala, A.A. Sawanta, K. Jansena, J.W. Millera, D.R. Cocker, Atmos. Environ. 42, 4380-4392 (2008) 